\title{
Le
}

SECCIÓN: Educación y espacio
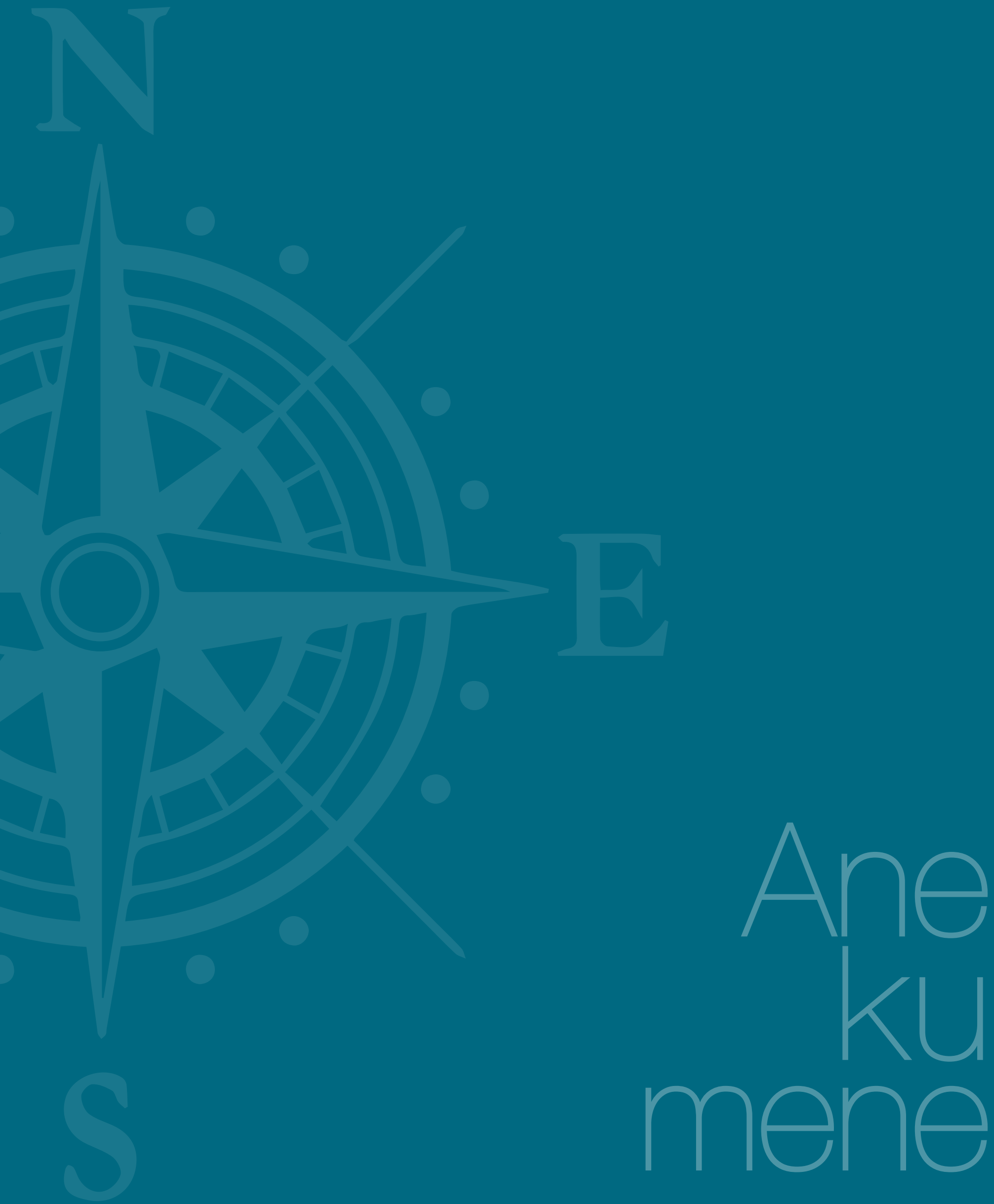


\section{Educação para a formação cidadã}

\section{Educación para la formación ciudadana Education for Civic Training}

Cristhian Moreira Brum*

Daniel Graciolli**

Tarcisio Dorn de Oliveira ${ }^{* * *}$

\section{Resumo}

A formação cidadã pensada do ponto dos estudiosos do espaço (neste caso, geógrafos e urbanistas) considerando a sua intervenção no espaço habitado, leva em conta a criação de novos cenários urbanos aliando teoria e prática. Esta formação cidadã deve permear conceitos que esbarram nas fronteiras das instituições de ensino permitindo a participação conjunta do morador da cidade e do acadêmico de arquitetura e urbanismo. Do ponto de vista da educação, a cidadania invade os cenários de qualquer formação técnica, em qualquer tempo e espaço, e deve ser vivida por todos com ampla liberdade e autonomia, teoria quase que impossível de ser vivenciada pelos sujeitos, visto que não nascemos com o sentimento de cidadania, este se instala em cada sujeito no decorrer de sua vida.

\section{Palavras-chave}

paisagem; espaço, tempo e grupo; Geografia e urbanismo

\footnotetext{
* Universidade Regional do Noroeste do Estado do Rio Grande do Sul - UNIJUI/RS. URI Campus de Frederico Westphalen. Bolsista CAPES.

** URI Campus de Frederico Westphalen/RS.

*** Universidade Regional do Noroeste do Estado do Rio Grande do Sul - UNIJUI/RS
} 


\section{Abstract}

From the point of view of those who study space (in this case, geographers and urban planners), considering their intervention in inhabited areas, civic education takes into account the creation of new urban scenarios by linking theory and practice. This civic education should permeate concepts that stumble on the borders of educational institutions, thus allowing the joint participation of the city's resident and the academicians of architecture and urbanism. From the point of view of education, citizenship invades the scenarios of any technical training, in any time and space, and must be lived by everyone with ample freedom and autonomy; this is a theory that is almost impossible for individuals to experience, since we are born with no sense of citizenship-individuals develop it throughout their lives.

\section{Resumen}

La formación ciudadana pensada desde el punto de vista de los estudiosos del espacio (en este caso, geógrafos y urbanistas) considerando su intervención en el espacio habitado, tiene en cuenta la creación de nuevos escenarios urbanos al vincular la teoría y la práctica. Esta formación ciudadana debe permear conceptos que tropiezan en las fronteras de las instituciones de enseñanza permitiendo la participación conjunta del residente de la ciudad y del académico de arquitectura y urbanismo. Desde el punto de vista de la educación, la ciudadanía invade los escenarios de cualquier formación técnica, en cualquier tiempo y espacio, y debe ser vivida por todos con amplia libertad y autonomía, teoría casi que imposible de ser vivenciada por los sujetos, ya que no nacemos con el sentimiento de ciudadanía, sino que este se instala en cada sujeto durante el transcurso de su vida.

\section{Keywords}

Landscape; space, time and group; geography and urbanism

\section{Palabras clave}

Paisaje; espacio, tiempo y grupo; geografía y urbanismo 
Este texto apresenta uma reflexão sobre cidadania como parte do processo de formação do sujeito. Ora, sabemos que o ser humano não nasce cidadão, ele tem em si a impressão de uma marca genética, e por sua composição hereditária é que se diferencia como ser biológico. Mas é a partir de sua inserção no mundo, desde suas primeiras horas de vida, que ele começa a construir suas maneiras próprias de sentir, fazer e decidir. É através do meio onde ele vive que o sujeito inicia sua formação como cidadão, se apoiando em bases sólidas a partir de sua cultura, do berço familiar onde nasceu ou se criou e da escola onde foi iniciada sua formação e da continuidade deste processo, enfim, nada é estanque e isolado, é um processo contínuo e integrado.

A complexidade da palavra cidadania faz-nos refletir sobre este tema de uma forma constante, isso se deve ao fato de ser esta, uma palavra especificamente pessoal, como um sentimento, um comportamento único e próprio de cada sujeito, porém que se desenvolve e só existe no fazer coletivo. Surge das relações entre os sujeitos, entre o sujeito e o seu grupo familiar ou social, entre os grupos, quaisquer que sejam suas origens. Entender seus significados é parte deste processo de formação cidadã, é uma garantia de que estas reflexões evoluem com o desenvolver das relações humanas e sua evolução.

Quando nos referimos a esta questão, podemos destacar que o advento do século XXI trouxe inúmeras mudanças para a sociedade, refletidas nas relações humanas e no mercado de trabalho (Ficagna \& Orth, 2010). Nesse contexto, Severino (2000) observa que:

A humanidade vive um momento de sua história marcado por grandes transformações, decorrentes sobretudo do avanço tecnológico, nas diversas esferas de sua existência, sendo, na produção econômica dos bens naturais, nas relações políticas da vida social ou na construção cultural. (p.65).

Assim, Araújo e Puig (2007), escrevem que compreender o que são valores e como cada um e todos os seres humanos se apropriam da cultura e se inserem no mundo faz parte do rol de preocupações daqueles interessados em estudar o citado binômio educação e valores e suas possíveis relações.

No que se refere a educação, para Ficagna e Orth (2010, apud Soares, Ribeiro, Vilhena, Munhoz \& Stefenon, 2012 p.1859), "as mudanças começam pela escola, partindo do princípio de que todos passam ou deveriam passar por ela, onde as grandes transformações não se originam apenas de grandes feitos, mas de iniciativas do dia a dia, simples e persistentes".

Ainda os autores supracitados, observam que é essencial que a escola provoque os alunos a desenvolverem a capacidade de compreenderem e atuarem no mundo em que vivem, onde é preciso dar-lhes informações e a formação para que possam atuar como cidadãos, organizando-se, defendendo seus interesses e da coletividade. Para isso, a educação em valores precisa ser encarada como um processo, ou seja, os valores não nascem com as pessoas, pois não são predeterminados geneticamente e nem são internalizados de fora para dentro do sujeito (Araújo \& Puig, 2007).

Este mesmo autor adverte que caso a escola deseje formar eticamente crianças e jovens, é preciso entender que uma ideia se torna um valor para alguém quando se projeta sentimentos positivos sobre essa ideia. Consequentemente, os sentimentos positivos projetados despertam a disposição de repetir os comportamentos desejáveis, não como um hábito mecânico, mas sim, como algo que se deve aprender e que, além disso, refletir e avaliar segundo as motivações que nos são apresentadas pelas emoções e razões (Araújo \& Puig, 2007).

A ideia é formar na escola sujeitos preparados para o mundo, seres autônomos que saibam elaborar seus próprios conceitos e saibam discernir entre as situações que se apresentam quais as que podem contribuir para com o bem de todos e quais as que visam um sujeito ou uma situação individualizada sem pensar no coletivo. Formar não apenas para a vida adulta, mas que vivam cada momento de suas vidas buscando compreender qual o seu papel e o seu lugar nesse mundo.

Sendo assim, faz-se necessário pensar a escola, conforme análise das autoras Brito e Lopes (2014), que apontam a escola como uma continuidade do lugar em que vivemos e que se deve exercer a cidadania dentro e fora dela, contando com o engajamento de toda a comunidade escolar no ato de promover a participação e dar voz e vez à criança. A partir do instante em que a criança consegue expressar sua opinião, deve fazê-la sem medo, procurando sempre questionar a realidade, promovendo uma convivência democrática, através das regras de funcionamento e normas de conduta. A ideia de que a escola estimule essas condutas deve se assentar em proposições que permitam que cada um analise, avalie as suas ações e compreenda ou sua realização na busca da construção do bem comum.

Segundo Ficagna e Orth (2010 apud Soares et al., 2012, p.1861):

Para que uma sociedade plenamente democrática seja construída é essencial que a escola propicie aos educandos que recebam informações e formação que os possibilitem exercer sua cidadania, convertendo problemas em oportunidades e estejam aptos a se organizar em busca da defesa de seus interesses e procurar soluções através do diálogo e da negociação, acatando as regras estabelecidas.

Neste sentido deve ser reforçado o diálogo permanente que deve existir na vida em sociedade através dos diversos grupos dos quais fazemos parte, e inclusive na escola no cotidiano das ações. A construção de soluções requer que seja realizado esforço conjunto tendo abertura para o diálogo premente, pois não existindo uma só verdade pronta e acabada, a cada situação devem ser construídas as possibilidades de busca das 
verdades. Assim os problemas precisam e podem ser resolvidos com a permanente atuação dos sujeitos envolvidos. E na escola estes são os próprios alunos, os professores e todo o grupo que atua na mesma.

\section{A escola vista como espaço de cidadania}

A escola pode promover essa busca de entendimento entre os vários sujeitos e construir alternativas para aprendizagens adequadas ao bem viver, tendo acesso ao conhecimento e construindo valores? Segundo Libâneo (2011), a escola não é a única responsável pela transformação da sociedade, porém a luta pedagógica é uma parte das lutas políticas, onde a relação da escola com a realidade social é bem dinâmica. Isso possibilita a luta por melhores condições de vida, o surgimento de líderes políticos que estejam representando as classes populares, a desmistificação dos conteúdos das matérias, e contribui, de tal modo, efetivamente para a substituição de alguns modelos sociais e éticos por outros.

Outros autores e estudiosos da escola e da educação também se manifestam por estes caminhos. No caso de Severino (2000, p.68) a educação, não poderá mais "ser vista como processo mecânico de desenvolvimento de potencialidades, ela será necessariamente, um processo de construção, ou seja, uma prática mediante a qual os homens estão se construindo ao longo do tempo". E para tanto reforçamos a proposição da importância do diálogo e do significado que permite ao produzir alternativas que interessam ao grupo e à sociedade e que promovam o exercício critico constante diante das situações que se apresentam.

Seguindo este mesmo raciocínio (Libâneo, 2011) acentua que a escola é o lugar onde o educador crítico sabe da importância de promover a integração de um trabalho escolar pedagógico, psicossocial e sociopolítico, pois é na escola que as camadas populares terão acesso ao saber elaborado, mas é também lá que ele vai aprender a socializar-se.

Ainda para o mesmo autor no que se refere ao ensino técnico, este deve dar ao educando uma formação cultural e científica de qualidade e a socialização vai propiciar-lhe a formação da sua personalidade social, em busca de emancipação das relações de dominação vigorantes. Nesse sentido, pensando na educação e sua inserção na vida social dos sujeitos é que Severino (2000, p. 65) destaca que:

A educação, como processo pedagógico sistematizado de intervenção na dinâmica da vida social, é considerada hoje objeto priorizado de estudos científicos com vistas à definição de políticas estratégicas para o desenvolvimento integral das sociedades, onde é entendida como mediação básica da vida social de todas as comunidades humanas.

Saviani (2008), escreve que o homem é o único ser que precisa adaptar a natureza a si, de acordo com suas necessidades, pois é através do trabalho que o homem age sobre a natureza. A relação dos homens ou do conjunto da sociedade com a natureza decorre do tipo de relação existente entre os homens, para assim fazer uso indiscriminado dos recursos naturais ou para buscar alternativas para uma atuação na e com a natureza que possa preservar os cuidados para com a vida.

É preciso ressaltar aqui que o fato do homem adaptar a natureza para atender às suas necessidades é uma forma de destacar que estas adaptações se dão pela constante inquietação inerente ao mesmo. 0 homem não se acomoda com o existente, sua insatisfação lhe categoriza como um ser reflexivo e por isso, um ser insatisfeito. Graças a esta inquietante situação é que contamos com o desenvolvimento da humanidade e suas consequentes transformações. Pode-se imaginar a importância da educação neste processo de inquietude e insatisfação. Sujeitos educados propõem transformações responsáveis aos seus pares e ao meio onde vivem.

Por este motivo é que Henz (2010) afirma que o ser humano precisa aprender tudo ao nascer e se constituir sócio culturalmente. E é através da educação que os seres humanos vão se formando ao interagir com o mundo a sua volta e com seus semelhantes. Neste sentido se insere a discussão pela constituição da cidadania que requer atitudes responsáveis e que considerem a preservação da vida humana e da natureza, com condições de equilíbrio que evite a destruição e que fundamente a justiça social como paramento para o desenvolvimento.

Vieira (1996) analisa que é na vida escolar que os educandos vão ter efetivamente as primeiras oportunidades para exercer essa cidadania, sendo a escola uma organização, que compõe uma coletividade que visa certos objetivos e estabelece certas condutas sociais para que esses objetivos sejam concretizados. Assim, a escola "exibe conflitos entre suas próprias necessidades e as necessidades das demais pessoas, entre racionalidade e irracionalidade, entre relações formais e relações informais, entre direção e corpo docente, entre corpo discente e corpo de funcionários" (Vieira, 1996, p. 112).

\section{A cidadania como princípio de igualdade na escola}

A origem da cidadania veio com o surgimento de cidade ou pólis grega, onde ser cidadão se restringia à apenas alguns homens que podiam ter participação política, vivendo uma vida em coletividade com os direitos e deveres. Em uma estrutura democrática, as decisões eram tomadas mediante a discussão dos fatos, com argumentação e sem violência, todavia, não estavam inclusos como cidadãos os homens escravos, as mulheres e as crianças (Manzini Covre, 2002). Ao longo da história a cidadania assume diversas facetas pois que é construída historicamente, e assim sendo não é algo dado, mas situado no tempo e no espaço das nossas vidas. 
O Brasil, em 1988, elaborou a sua Constituição Federativa, denominada Constituição Cidadã, fixando um novo quadro de leis relativas aos direitos e deveres dos cidadãos, se comprometendo em assegurar o exercício dos direitos sociais e individuais, a liberdade, a segurança, o bem-estar, o desenvolvimento, a igualdade e a justiça como valores supremos de uma sociedade fraterna, pluralista e sem preconceitos. (Constituição da República Federativa do Brasil, 1988/2001).

Em seus artigos destaca-se o artigo $5^{\circ} \mathrm{em}$ que diz que "todos são iguais perante a lei, sem distinção de qualquer natureza, garantindo-se aos brasileiros e aos estrangeiros residentes no País a inviolabilidade do direito à vida, à liberdade, à igualdade, à segurança e à propriedade..." E o artigo 60 "São direitos sociais a educação, a saúde, a alimentação, o trabalho, a moradia, o lazer, a segurança, a previdência social, a proteção à maternidade e à infância, a assistência aos desamparados". (Constituição da República Federativa do Brasil, 1988/2001).

Conforme as autoras Brito e Lopes (2014) a Constituição Brasileira de 1988, conhecida conforme referido anteriormente como a constituição cidadã foi:

A constituição que mais considerou a questão dos direitos humanos oportunizando a abertura de políticas públicas centradas na proteção e na promoção dos direitos humanos. Entretanto, o exercício da cidadania não é uma conquista de tempos passados e fatos históricos presos em suas épocas, pois ainda hoje, deve-se buscar e lutar pelos ideais de uma sociedade justa e igualitária para todos os homens através do cumprimento dos deveres e na exigência e reivindicação dos direitos. (p.2).

Nesse contexto, de acordo com Pinsky (2013), cidadania não é uma definição estanque, mas um conceito histórico, o que significa que seu sentido varia no tempo e no espaço. Há diferenças em ser cidadão na Alemanha, nos Estados Unidos ou no Brasil, não apenas pelas regras que definem quem é ou não titular da cidadania, mas também pelos direitos e deveres distintos que caracterizam o cidadão em cada um dos Estados - Nacionais contemporâneos.

Avançando com esta caracterização, Candau (2012) afirma que a questão dos direitos humanos é fundamental para se tratar as principais problemáticas sociais da contemporaneidade. Deve abranger não só a realidade local, mas a global, não só da vida individual, mas também da comunitária e coletiva.

Em sentido genérico pensando a vida social as questões estão postas, embora nem sempre atendidas e cumpridas. Mas no caso da escola e da educação escolar que é o motivo que nos chama a análise, há detathes que se desdobram e que precisam ser constantemente percebidos para o andamento das atividades escolares. Se trata desde atitudes, comportamentos, valores ética e moral, mas também do que é ensinado na escola e de como é ensinado. Além disso, é fundamental saber para que se ensinam determinados conteúdos e a quem são ensinados. Todos estes aspectos ${ }^{1}$ devem ser considerados ao se pensar a cidadania na escola. Para Ficagna e Orth (2010, apud Soares et al., 2012, p.1861) é necessária a discussão dessa questão pois,

a simples transmissão dos conteúdos e da cultura construída na escola, não prepara o aluno para as exigências da sociedade atual, enquanto o mundo anda muito rápido fora do contexto escolar, o aluno fica entre quatro paredes, passivamente sentado, ouvindo os professores falarem ou realizando exercícios.

Reafirmamos que é importante a clareza de que não se trata de formar para o futuro, quando este estudante de hoje for adulto e ingresse no mundo do trabalho. Mas é preciso criar as condições e oferecer as oportunidades para que a cidadania seja exercitada desde já, nos limites da própria escola. Assim, é urgente que um novo sentido de cidadania seja construído e o lugar mais favorável para que isso aconteça é a escola, pois é onde as crianças e adolescentes passam uma boa parte de seu dia, é lá que passam a conviver com outras pessoas, fora de sua família e é lá que supostamente são preparadas para viver em sociedade (Ficagna \& Orth, 2010 apud Soares et al, 2012).

Ainda as autoras Brito e Lopes (2014) observam que:

Pensar numa sociedade em que realmente todos seriam respeitados e considerados iguais perante a lei parece ser um sonho distante, mas é preciso pensar numa educação para a cidadania, uma educação preocupada em formar um ser humano livre, responsável, autônomo, habilitando aos educandos a terem posicionamentos esclarecidos e críticos relativamente às questões do mundo de hoje. (p.2).

A cidadania consiste num princípio de igualdade distendido em direitos que, através das lutas sociais, vão sendo adicionados aos poucos, onde esses direitos podem ser civis, políticos ou sociais (Vieira, 1996). E para o autor, o exercício da cidadania dá-se pela participação do sujeito em todos os aspectos da organização e da condução da vida privada e coletiva e à habilidade que este sujeito adquire para operar escolhas, onde o aprendizado da cidadania implica em liberdade, autonomia e responsabilidade.

Conforme Candau (2012) são muitas as referências à importância do direito a educação, mas poucas as reflexões que tem se dedicado a aprofundar o conteúdo deste direito numa perspectiva ampla, sem reduzi-lo a escolarização simplesmente. Decorre daí que a quantidade (de vagas) para o acesso à escola tem sido apregoado como avanços importantes, que o são mesmo, isso ninguém pode negar. Mas a qualidade não tem conseguido acompanhar e há muito desequilíbrio e muitos desafios para consegui-lo. É certo que é possível afirmar que o desenvolvimento do

1 Ver Callai, H. C. (2013). Educação Geográfica- reflexão e prática. Ijui. Editora Unijui. 
direito a educação no nosso país, passa certamente por um processo acelerado nas últimas décadas. E pode ser caracterizado por duas ênfases: a expansão da escolarização e a afirmação da construção de uma educação escolar comum a todos, na perspectiva da afirmação da igualdade e na busca da justiça social.

Entretanto, a educação escolar não pode ser reduzida a um produto que se negocia na lógica do mercado; nem ter como referência quase que exclusivamente a aquisição de determinados conteúdos, por mais socialmente reconhecidos que sejam. Deve ter como horizonte a construção de uma cidadania participativa, a formação de sujeitos de direito, o desenvolvimento da vocação humana de todas as pessoas nela implicadas (Candau, 2012). Os conteúdos são nesse caminhar os meios para constituição de sujeitos que exerçam a sua cidadania de modo pleno.

\section{Considerações finais}

A humanidade busca constantemente estar em um estado de conforto que lhe propicie satisfação, quer individual ou com vistas ao que é coletivo. Porém, a busca pelo que lhe parece seguro e estável implica em transformações permanentes, o que pareceria antagônico: a busca pelo que parece estável ao ser, através de constantes transformações. Mas assim é e, sempre será em consequência da própria origem reflexiva e questionadora do ser humano, onde se interelacionam conceitos ligados a vida cotidiana, ao espaço onde vive e ao conhecimento científico que é produzido pela humanidade ao longo da sua história.

Estes espaços de vivência dos sujeitos, que vão além do que significa o espaço de ocupação ou sua identificação geográfica, são considerados como solo fértil para o nascimento de novas ideologias sociais, de novas configurações de redes culturais compostas de cidadãos com ideias e ideais próprios voltados para as comunidades.

Neste contexto de transformação, insere-se a educação, como processo contínuo durante toda vida do sujeito. Aprimorar e buscar complementar este processo tem como consequência lógica, as relações com o mundo e com os outros sujeitos que fazem parte do meio. Sendo assim, a família, a escola, o trabalho, os núcleos de convivência social, permeiam as esferas desta construção do sujeito e compõem as bases do processo educacional do mesmo, dando forma e cor ao cenário que vai se instituindo como pano de fundo de sua vivência, onde ele, o sujeito, não é mais um ator solitário, mas sim parte de um todo, composto por diretrizes comuns que norteiam o fazer cidadão.

O ser cidadão é a garantia que a humanidade possui para continuar sua evolução. Desta forma, a responsabilidade por um mundo ético e habitável está pautada nas relações entre os sujeitos e na forma como estas são instituídas e administradas. Faz-se necessário perceber de que a cidadania é um processo contínuo de aprendizagem e que só será entendido por todos, na medida em que os sujeitos compreenderem que deve existir uma construção coletiva e solidária, sem preconceitos instituídos, sem marcas entre territórios, sem tempos excludentes, e que o objetivo principal entre os atores seja a construção de um lugar onde todos os sujeitos possam viver e se desenvolverem em sociedade participativa.

A partir destes enunciados foram desenvolvidas ações com a integração entre o meio acadêmico, as comunidades e o poder público para contribuir com construção da cidadania de todos os sujeitos envolvidos. As atividades realizadas são: - estudo prévio do polígono de atuação onde se define a experiência de intervenção; - programação de audiências públicas para detectar os valores sociais e culturais da comunidade por meio de diagnósticos; - recolhimento de documentos e materiais informativos; - lançamento de hipóteses arquitetônicas urbanísticas sustentáveis que incluam uma visão prospectiva dos impactos gerados. No desenvolvimento do processo os resultados apresentados não são apenas materiais, mas simbólicos inclusive, e que refletem na formação cidadã. 


\section{Referências}

Araújo, U. F. \& Puig, J. M. (2007). Educação e valores: Pontos e Contrapontos. (V. A. Arantes, org.) São Paulo: Summus.

Brito, A., C. de, \& Lopes, M. E., (2014). O papel da educação escolar para o exercício da cidadania. Revista Primus Vitam,. 7, (2), pp.1-14.

Candau, V. M. F., (2012). Direito à educação, diversidade e educação em direitos humanos. Educação Sociedade, 33, (120), pp. 715-726.

Constituição da República Federativa do Brasil de 1988. (2001). [Coleção Saraiva de Legislação]. (21a ed.). São Paulo: Saraiva.

Henz, C. I., (2010). Dialogando sobre cinco dimensões para humanizar a educação. Em B. A. Andreola; E. L. Pauly; L. G. Kronbauer \& M. A. Orth. (orgs.). Formação de educadores: da itinerância das universidades à escola itinerante (pp. 49-62). Ijuí: Ed. Unijuí.

Lei no 9394, de 20 de dezembro de 1996. Estabelece as diretrizes e bases da educação nacional. Diário Oficial da União. Brasília, DF.

Libâneo, J. C., (2011). Democratização da Escola Pública: a pedagogia crítico-social dos conteúdos. (26 ed.). São Paulo: Edições Loyola.

Manzini Covre, M. de L., (2002). O que é cidadania. [Coleção Primeiros Passos]. São Paulo: Brasiliense.

Pauly, E. L., (2010). O adolescer na democracia: reflexões político-pedagógicas sobre a formação moral para a cidadania. Em: B. A. Andreola; E. L. Pauly; L. G. Kronbauer \&M. A. Orth. (orgs.). Formação de educadores: da itinerância das universidades à escola itinerante (pp.129-153). ljuí: Ed. Unijuí.

Pinsky, J., \& Pinsky, C. B., (orgs.). (2013). História da Cidadania. (6. ed.). São Paulo: Contexto.

Severino, A. J., (2013). Educação, Trabalho e Cidadania: a educação brasileira e o desafio da formação humana no atual cenário histórico. São Paulo em Perspectiva, 2, (14), pp.65-71.

Soares, G. L.; Ribeiro, A. C.; Vilhena, T. F. de; Munhoz, J. M., \& Stefenon V. M., (2012). A formação do cidadão no ambiente escolar: Da conscientização à intervenção na própria realidade. Monografias Ambientais, 8, (8), pp.1858-1869.

Centro de informação das Nações Unidas Rio de Janeiro [UNIC], (2000). Declaração Universal dos Direitos Humanos.. Recuperado em 7 de abril de 2016 de: http:// unicrio.org.br/img/DeclU_D_HumanosVersolnternet.pdf

Vieira, E.(1996). Sociologia da Educação: reproduzir e transformar. (3 ed.). São Paulo: FTD. 